\title{
SIMULATION STUDY ON USING OPEN NUCLEUS BREEDING SCHEME FOR GENETIC CHECKED IMPROVEMENT OF WEANING WEIGHT IN BARKI SHEEP WITH SPECIAL EMPHASIS ON FLOCK SIZE \\ Salwa I.El-Wakil \\ Animal and Poultry Breeding Dept., Desert Research \\ Centre, El-Matareya, Cairo, Egypt. \\ Email:salwa_elwakil@yahoo.com
}

\begin{abstract}
The present article investigated how the expected genetic gain of weaning weight changed in relation to the size of the nucleus and commercial flocks in order to develop a suitable strategy for improving meat production in Barki sheep. The original body weight data were collected from the Barki sheep flock of the Desert Research Centre from 1963 to 2005 with a total number of 1046 animals (542 females and 504 males) progenies of 163 sires and 557 dams. The simulated sets of data were generated from the original data and designed to construct two scenarios of an open nucleus breeding scheme each consists of a nucleus and 5 contributing commercial flocks. The first scenario concerned with small flock size (1500 ewes and 50 sires in the nucleus flock together with 3000 ewes and 100 sires in each commercial flock), while the second scenario dealt with large flock size (3000 ewes and 100 sires in the nucleus flock in addition to 6000 ewes and 200 sires in each commercial flock). The open nucleus breeding scheme was also simulated to allow for the exchange of superior sires among tires in both directions. Four generations of progenies were obtained by selection of sires and dams for the next generations. The annual genetic gain as a response to selection for weaning weight was also calculated.

Results of breeding values of sires, dams and offspring as well as average weaning weight indicated no differences between large and small flock sizes despite the slight increase observed in the small flock size throughout four generations. Breeding values of sires, dams and offspring as well as the average weaning weight tended to increase as generations increased from first (G1) to the fourth generation (G4) in nucleus and commercial flocks in both small and large population size. Selection for weaning weight through applying open nucleus breeding scheme for four generations increased average weaning weight from $19.02 \mathrm{~kg}$ to $32.58 \mathrm{~kg}$ (by $71.3 \%$ ) in the nucleus flock and from $16.33 \mathrm{~kg}$ to $28.91 \mathrm{~kg}$ (by $77.0 \%$ ) in the commercial flocks of the small population size. The corresponding values for the large population size were $18.67 \mathrm{~kg}$ to $32.50 \mathrm{~kg}$ (by $74.1 \%$ ) in the nucleus flock and from $16.30 \mathrm{~kg}$ to 28.56 $\mathrm{kg}$ (by $75.2 \%$ ) in commercial flocks. The annual rate of genetic gain for average weaning weight tended to decrease as the generation advanced from G1 to G4 in both small and large population sizes.

There is a considerable increase in the genetic response in both large and small population sizes despite the slight difference in the annual genetic gain of weaning weight occurred in small flock sizes. The study argued that without increasing the number of animals in the nucleus, breeders could accelerate genetic progress in productive traits by annually screening elite animals from commercial flocks, ensure high selection intensities and shorter generation intervals together with the accuracy of selection decisions.
\end{abstract}

Keywords: Open nucleus breeding scheme, Genetic improvement, Weaning weight, Barki sheep 


\section{INTRODUCTION}

Genetic improvement of indigenous breeds is an important component of the development of a viable sheep industry. Barki sheep which is dominated in the north western coast (NWC) of Egypt has been subjected to harsh climatic conditions and prolonged feed shortage particularly in dry summer season. There is no genetic structure in the population to facilitate the dissemination of genetic progress. Nucleus schemes have been proposed as a good strategy for genetic improvement of small ruminants in developing countries (Hodges, 1990; Kiwuwa, 1992). Consequently, nucleus breeding scheme could be developed to play a leading role in the genetic improvement of Barki sheep. The nucleus breeding systems are also used when a set of outstanding sires are not available, and there is need to produce better sires for breeding purposes. Applying this system for indigenous breeds can make a significant contribution to the conservation and upgrading of local genetic resources. The scheme operates to accurately select the superior males and females according to their genetic merit (breeding value) to be parents for the next generation and disseminate those selected sires down to the commercial flocks (James, 1977; Smith, 1988). Open nucleus breeding scheme allows for the exchange of sires between nucleus and commercial flocks in both directions (Jackson and Turner, 1972).

The optimum size of the nucleus flock is necessary not only to make sizeable selection gains but also to meet the requirements of farmers outside the nucleus scheme. Adopting of such breeding plan is a long term in nature and costly to implement. On the other hand, records obtained from Barki sheep flock of the Desert Research Centre while extended for more than fourty years, it is insufficient to satisfy the requirement of constructing the nucleus breeding scheme. Thus, the present article used the simulation technique to supply larger set of data. Moreover, there is need to evaluate various alternatives to enable the decision maker to endorse the optimal breeding plan for improving Barki sheep before widespread implementation. Results obtained from the original data indicated that selection based on weaning weight might be more effective, compared with birth and yearling weights, hence weaning weight would be the selection objective for the proposed nucleus breeding scheme (El-Wakil et al., 2009). Therefore, the present article used the simulation technique to examine alternative breeding structures and addresses specifically how the expected genetic gain of weaning weight changed in relation to both the size of the nucleus and that of the commercial flocks in order to introduce a suitable strategy for improving meat production in Barki sheep.

\section{MATERIALS AND METHODS}

\section{Source of Data}

The original body weight data used in the present study were collected from the Barki sheep flock raised at Ras ElHekma (RHRS), from 1963 to 1972, and Maryout Research Stations (MRS), from 1973 to 2005. Both RHRS 
and MRS are belong to the Desert Research Centre and located at the northwestern coast of Egypt (NWC); RHRS at 250 kilometers west of Alexandria while MRS at 35 kilometers west of Alexandria. In 1972, the sheep flock at RHRS moved to MRS. Flock management was almost the same in RHRS and MRS (El-Wakil et al., 2009). Body weight was recorded from birth till the animal was removed from the flock. Weaning weight was linearly adjusted to 120-day weaning weight of each lamb.

The simulated sets of data were generated from statistical and genetic estimates resulted from the original data with a total number of 1046 animals (542 females and 504 males) progenies of 163 sires and 557 dams. The proposed scheme was simulated as closely as possible to the actual production system prevailing in the NWC to allow for lambing once a year when the new born ram lambs would be available for mating at the age of 16 months.

\section{Simulation procedure}

The current study dealt with simulating an open nucleus breeding scheme consists of a nucleus flock linked with 5 contributing commercial flocks. The simulated data concerned with the size of both nucleus and commercial flocks in which larger flock size were twice as much as that of smaller flock size. Populations of Barki sheep with one record of weaning weight for each animal were generated with assumed mean (0) and variance (1) using the Monte Carlo simulation technique of SAS (2004). For the simulated weaning weight data, parametric values were assumed for phenotypic (19.01), additive genetic (7.75) and residual variances (11.2) as well as the heritability (0.41) according to El-Wakil et al. (2009). According to Analla et al. (1995), the expected genetic value of the progeny $\left(g_{i}\right)$ is assumed to be equal to the average genetic values of the parents [sire $\left(g_{s}\right)$ and dam $\left(g_{d}\right)$ ] plus a deviation due to the Mendelian sampling as follows:

$$
g_{i}=0.5\left(g_{s}+g_{d}\right)+X \sqrt{\left(0.5 h^{2} \sigma_{p}^{2}\right)}
$$

Where $g_{i}$ is equal to the expected genetic value of an individual $i,\left(g_{s}\right)$ and $\left(g_{d}\right)$ are the genetic values of the parents (sire and dam, respectively); $X$ is a random number taken from normal distribution with mean 0 and variance 1 ; $\mathrm{h}^{2}$ is the heritability, and $\sigma_{p}^{2}$ is the phenotypic variance.

The genetic values for the first simulated population (producer flock) were taken randomly from a normal distribution with mean zero and variance $\sigma_{g}^{2}=h^{2} \sigma_{p}^{2}$ where $\sigma_{g}^{2}$ is the genetic variance and $\sigma_{p}^{2}$ is the phenotypic one. Preliminary analyses were conducted and assigned birth year as important fixed effect. The producer populations were further analyzed using multiple trait animal model (MTDFREML) proposed by Boldman et al. (1995) for the fixed (year of birth, 10 levels) and random effects (animal, sire and dam) in order to estimate the heritabilities of weaning weight as well as breeding values for sires, dams and their offspring.

The improvement of nucleus and commercial flocks occurred as a result of selecting rams and ewes and promoting them according to their breeding values for four successive generations. Improved animals produced from the nucleus flock were disseminated to commercial flocks. Selection is practiced mainly in rams while little selection of dams was performed just to 
maintain the fixed number of all flocks. The open nucleus breeding scheme allows for the exchange of superior sires between nucleus and commercial flocks in both directions. The following flow charts (Figs. 1 and 2) showed the process of simulating the open nucleus breeding scheme with the large and small flock size. The same procedures were repeated in the four generations. The annual genetic gain as a response to selection for weaning weight is calculated as a percentage of an increase in average weaning weight from a given generation to that of the following one.

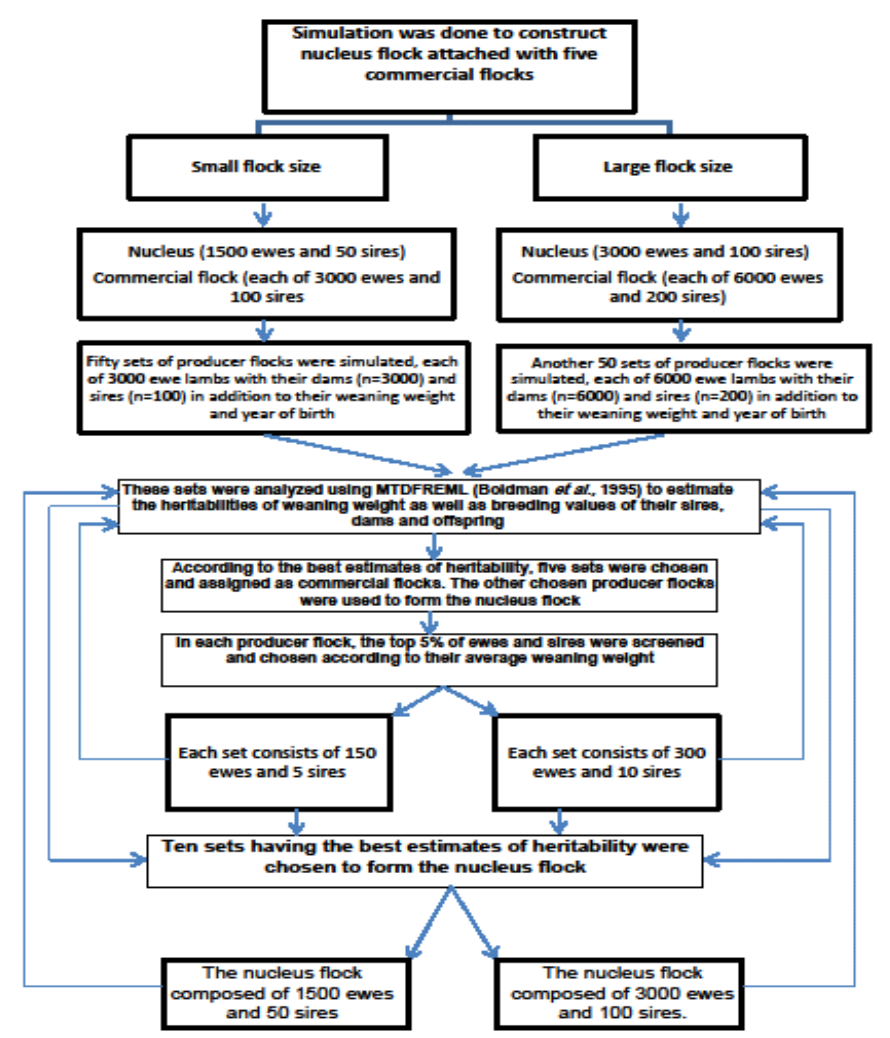

Figure (1). The procedure implemented to simulate the formulation of the nucleus breeding scheme with the large and small flock size. 


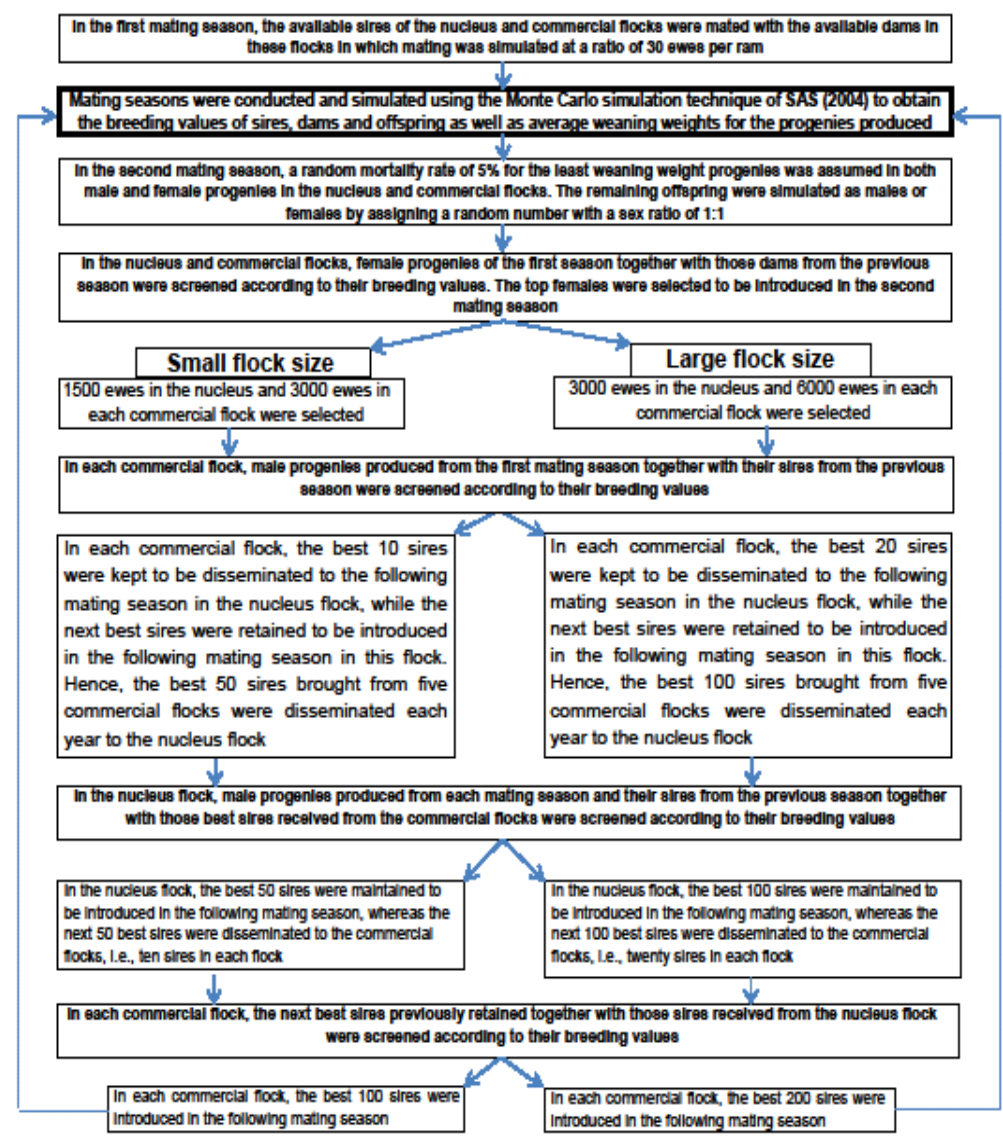

Figure (2). The procedure implemented to simulate producing generations of animals in the nucleus breeding scheme with the large and small flock size. 


\section{RESULTS AND DISCUSSION}

Tables (1 and 2) showed results of breeding values of sires, dams and offspring as well as average weaning weight obtained from two tires open nucleus breeding scheme with large (3000 ewes in the nucleus flock and 6000 ewes in each commercial flock) and small population size (1500 ewes in the nucleus flock and 3000 ewes in each commercial flock). The tabulated results revealed a consistent trend; a finding which provides confidence in the simulated data obtained. Generally, no differences were indicated between large and small population sizes in the proposed nucleus breeding scheme despite the slight increase observed in the small population size throughout four generations.

Breeding values of sires, dams and offspring as well as the average weaning weight tended to increase as generations increased from first (G1) to the fourth generation (G4) in nucleus and commercial flocks in both small and large population size (Tables 1 and 2). Selection for weaning weight through applying open nucleus breeding scheme for four generations increased average weaning weight from $19.02 \mathrm{~kg}$ to $32.58 \mathrm{~kg}$ (by $71.3 \%$ ) in the nucleus flock and from $16.33 \mathrm{~kg}$ to $28.91 \mathrm{~kg}$ (by $77.0 \%$ ) in the commercial flocks of the small population size (Table 1). The corresponding values for the large population size (Table 2) were $18.67 \mathrm{~kg}$ to $32.50 \mathrm{~kg}$ (by $74.1 \%$ ) in the nucleus flock and from $16.30 \mathrm{~kg}$ to $28.56 \mathrm{~kg}$ (by $75.2 \%$ ) in commercial flocks.

The annual rate of genetic gain for average weaning weight tended to decrease as the generation advanced from G1 to G4 in both small and large population sizes (Tables 1 and 2). The reason for such decrease probably due to the improvement occurred in nucleus and commercial flocks as a result of decreasing the selection differential from $\mathrm{G} 1$ to $\mathrm{G} 4$ in both large and small population sizes. The selection differential while was the highest between unimproved animals in G1 and improved ones in G2, it was the least between G3 and G4. In case of nucleus flock in the small population size (Table 1), as the genetic improvement proceeds, the selection differential tend to decrease as a result of decreasing the gap between unimproved and improved animals, keeping in mind that the annual rate of genetic gain in weaning weight increased in G2 by $26.1 \%$ compared with corresponding value in $\mathrm{G} 1$. The annual rate of genetic gain in weaning weight reached the least value of $14.9 \%$ between G3 and G4. That trend appeared to be consistent in nucleus and commercial flocks in both small and large population size (Tables 1 and 2). Similar trend was observed in the Egyptian buffaloes (Abdel-Salam et al., 2010). 
Table 1. The overall average weaning weight (Av. WW) and its breeding values (BV) for sires, dams and offspring in the nucleus and commercial flocks involved in the open nucleus breeding scheme of small size flocks in four generations (G1 to G4).

\begin{tabular}{|c|c|c|c|c|c|}
\hline Flock & & G1 & G2 & G3 & G4 \\
\hline \multirow{4}{*}{ Nucleus flock } & Sire BV & 4.95 & 13.61 & 18.51 & 22.41 \\
\hline & Dam BV & 0.02 & 1.84 & 5.52 & 10.29 \\
\hline & Offspring BV & 2.71 & 7.67 & 12.04 & 16.27 \\
\hline & Av. WW & 19.02 & $\begin{array}{c}23.98 \\
(26.1 \%)\end{array}$ & $\begin{array}{c}28.35 \\
(18.2 \%)\end{array}$ & $\begin{array}{c}32.58 \\
(14.9 \%)\end{array}$ \\
\hline \multicolumn{6}{|l|}{$\begin{array}{l}\text { Commercial } \\
\text { flocks }\end{array}$} \\
\hline \multirow{4}{*}{ C1 } & Sire BV & 0.00 & 9.05 & 13.70 & 17.83 \\
\hline & Dam BV & 0.00 & 1.78 & 4.52 & 7.95 \\
\hline & Offspring BV & 0.00 & 5.33 & 9.15 & 12.87 \\
\hline & Av. WW & 16.30 & $\begin{array}{c}21.64 \\
(32.8 \%)\end{array}$ & $\begin{array}{c}25.46 \\
(17.7 \%)\end{array}$ & $\begin{array}{c}29.18 \\
(14.6 \%)\end{array}$ \\
\hline \multirow{4}{*}{ C2 } & Sire BV & 0.00 & 8.39 & 13.30 & 17.44 \\
\hline & Dam BV & 0.00 & 1.51 & 4.05 & 7.43 \\
\hline & Offspring BV & 0.01 & 4.94 & 8.67 & 12.40 \\
\hline & Av. WW & 16.31 & $\begin{array}{c}21.25 \\
(30.3 \%)\end{array}$ & $\begin{array}{c}24.98 \\
(17.6 \%)\end{array}$ & $\begin{array}{c}28.71 \\
(14.9 \%)\end{array}$ \\
\hline \multirow{4}{*}{ C3 } & Sire BV & 0.00 & 8.64 & 13.30 & 17.56 \\
\hline & Dam BV & 0.00 & 1.59 & 4.26 & 7.68 \\
\hline & Offspring BV & 0.04 & 5.20 & 8.92 & 12.67 \\
\hline & Av. WW & 16.35 & $\begin{array}{c}21.51 \\
31.6 \%)\end{array}$ & $\begin{array}{c}25.23 \\
(17.3 \%)\end{array}$ & $\begin{array}{c}28.98 \\
(14.9 \%)\end{array}$ \\
\hline \multirow{4}{*}{ C4 } & Sire BV & 0.00 & 8.90 & 13.36 & 17.20 \\
\hline & Dam BV & 0.00 & 1.56 & 4.21 & 7.54 \\
\hline & Offspring BV & 0.02 & 5.13 & 8.70 & 12.42 \\
\hline & Av. WW & 16.33 & $\begin{array}{c}21.44 \\
(31.3 \%)\end{array}$ & $\begin{array}{c}25.00 \\
(16.6 \%)\end{array}$ & $\begin{array}{c}28.73 \\
(14.9 \%)\end{array}$ \\
\hline \multirow{4}{*}{ C5 } & Sire BV & 0.00 & 8.82 & 13.42 & 17.52 \\
\hline & Dam BV & 0.00 & 1.63 & 4.34 & 7.70 \\
\hline & Offspring BV & 0.05 & 5.33 & 8.86 & 12.63 \\
\hline & Av. WW & 16.36 & $\begin{array}{c}21.64 \\
(32.3 \%) \\
\end{array}$ & $\begin{array}{c}25.17 \\
(16.3 \%)\end{array}$ & $\begin{array}{c}28.94 \\
(15.0 \%)\end{array}$ \\
\hline \multirow{4}{*}{$\begin{array}{l}\text { Av. Commercial } \\
\text { flocks }\end{array}$} & Sire BV & 00.00 & 8.76 & 13.42 & 17.51 \\
\hline & Dam BV & 00.00 & 1.61 & 4.28 & 7.66 \\
\hline & Offspring BV & 0.02 & 5.19 & 8.86 & 12.60 \\
\hline & Av. WW & 16.33 & $\begin{array}{c}21.50 \\
(31.7 \%) \\
\end{array}$ & $\begin{array}{c}25.17 \\
(17.1 \%) \\
\end{array}$ & $\begin{array}{c}28.91 \\
(14.9 \%) \\
\end{array}$ \\
\hline
\end{tabular}


Table 2. The overall average weaning weight (Av. WW) and its breeding values (BV) for sires, dams and offspring in the nucleus and commercial flocks involved in the open nucleus breeding scheme of large size flocks in four generations (G1 to G4).

\begin{tabular}{|c|c|c|c|c|c|}
\hline Flock & & G1 & G2 & G3 & G4 \\
\hline \multirow{4}{*}{ Nucleus flocks } & Sire BV & 4.73 & 13.04 & 17.80 & 22.39 \\
\hline & Dam BV & 0.01 & 1.57 & 5.11 & 9.79 \\
\hline & Offspring BV & 2.36 & 7.34 & 11.41 & 16.19 \\
\hline & Av. WW & 18.67 & $\begin{array}{c}23.65 \\
(26.7 \%)\end{array}$ & $\begin{array}{c}27.72 \\
(17.2 \%)\end{array}$ & $\begin{array}{c}32.50 \\
(17.2 \%)\end{array}$ \\
\hline \multicolumn{6}{|l|}{ Commercial flocks } \\
\hline \multirow{4}{*}{ C1 } & Sire BV & 0.00 & 8.36 & 13.20 & 17.21 \\
\hline & Dam BV & 0.00 & 1.44 & 4.07 & 7.46 \\
\hline & Offspring BV & 0.00 & 4.96 & 8.60 & 12.36 \\
\hline & Av. WW & 16.23 & $\begin{array}{c}21.27 \\
(31.1 \%)\end{array}$ & $\begin{array}{c}24.91 \\
(17.1 \%)\end{array}$ & $\begin{array}{c}28.67 \\
(15.1 \%)\end{array}$ \\
\hline \multirow{4}{*}{ C2 } & Sire BV & 0.00 & 8.79 & 13.27 & 17.12 \\
\hline & Dam BV & 0.00 & 1.52 & 4.19 & 7.61 \\
\hline & Offspring BV & 0.00 & 5.21 & 8.81 & 12.43 \\
\hline & Av. WW & 16.29 & $\begin{array}{c}21.52 \\
(32.1 \%)\end{array}$ & $\begin{array}{c}25.12 \\
(16.7 \%)\end{array}$ & $\begin{array}{c}28.74 \\
(14.4 \%)\end{array}$ \\
\hline \multirow{4}{*}{ C3 } & Sire BV & 0.00 & 8.49 & 12.89 & 16.96 \\
\hline & Dam BV & 0.00 & 1.47 & 4.04 & 7.35 \\
\hline & Offspring BV & 0.00 & 4.95 & 8.46 & 12.15 \\
\hline & Av. WW & 16.23 & $\begin{array}{c}21.26 \\
(31.0 \%)\end{array}$ & $\begin{array}{c}24.77 \\
(16.5 \%)\end{array}$ & $\begin{array}{c}28.46 \\
(14.9 \%)\end{array}$ \\
\hline \multirow{4}{*}{ C4 } & Sire BV & 0.00 & 8.53 & 12.97 & 16.99 \\
\hline & Dam BV & 0.00 & 1.49 & 4.05 & 7.37 \\
\hline & Offspring BV & 0.03 & 4.98 & 8.48 & 12.15 \\
\hline & Av. WW & 16.34 & $\begin{array}{c}21.29 \\
(30.3 \%)\end{array}$ & $\begin{array}{c}24.79 \\
(16.4 \%)\end{array}$ & $\begin{array}{c}28.46 \\
(14.8 \%)\end{array}$ \\
\hline \multirow{4}{*}{ C5 } & Sire BV & 0.00 & 8.55 & 13.02 & 17.12 \\
\hline & Dam BV & 0.00 & 1.43 & 4.00 & 7.38 \\
\hline & Offspring BV & 0.10 & 5.05 & 8.55 & 12.15 \\
\hline & Av. WW & 16.41 & $\begin{array}{c}21.36 \\
(30.2 \%)\end{array}$ & $\begin{array}{c}24.86 \\
(16.4 \%)\end{array}$ & $\begin{array}{c}28.46 \\
(14.5 \%)\end{array}$ \\
\hline \multirow{4}{*}{$\begin{array}{l}\text { Av. Commercial } \\
\text { flocks }\end{array}$} & Sire BV & 00.00 & 8.54 & 13.07 & 17.08 \\
\hline & Dam BV & 00.00 & 1.47 & 4.07 & 7.43 \\
\hline & Offspring BV & 0.03 & 5.03 & 8.58 & 12.25 \\
\hline & Av. WW & 16.30 & $\begin{array}{c}21.34 \\
(30.9 \%)\end{array}$ & $\begin{array}{c}24.89 \\
(16.6 \%)\end{array}$ & $\begin{array}{c}28.56 \\
(14.7 \%)\end{array}$ \\
\hline
\end{tabular}

Generally, the expected genetic progress in open nucleus systems is more rapid than in equivalent single flocks due to increased additive genetic variation between levels (Mueller and James, 1984; Smith, 1988). The nucleus system may be thought of as a way of increasing the genetic variance in a population, and also making use of that extra genetic variance by selecting some animals from the base for nucleus use. Therefore, the optimum size of the nucleus flock is necessary not only to make sizeable selection gains but also to meet the requirements of farmers outside the 
nucleus scheme. A number of investigations have shown contradicting results regarding the impact of population size on the achieved genetic gain. AbdelSalam et al. (2010) indicated that increasing population size from 10,000 to 100,000 resulted in an increase in genetic gain of milk production from $64 \mathrm{~kg}$ to $73 \mathrm{~kg}$ in Egyptian buffaloes. Genetic gain was expected to vary in relation to both the dimension of the nucleus and that of the commercial population. In general, the larger the nucleus the higher the genetic gain (Gandini et al., 2014). On the other hand, larger population size is probably less elite compared with the smaller population size. It is reported that the rate of genetic progress in the whole breeding system depends, among other things, on the rate of genetic gain within the nucleus and the size of the selection differentials achieved will depend on the size of the population screened (Garrick et al., 2000; Bosso, 2006). A nucleus breeding scheme can therefore be relatively small in size and still have large impact, if well organized and operated properly (Syrstad, 1989; Garrick et al., 2000; Bosso, 2006). Furthermore, the variability in population size leads to a moderate decrease in genetic response and has a decreasing effect on the rate of inbreeding as well as increases the cost of maintaining these flocks. In N'Dama cattle, the increase in the size of the nucleus was associated with a decrease in the genetic response for milk yield and daily weight gain, indicating that a large nucleus size is not always advantageous (Bosso, 2006).

There is certainly a considerable increase in the genetic response in both studied large and small population sizes; however, the maximum size of a nucleus scheme is dependent on the facilities available. Thus, an in depth economic evaluation is required to find out the optimum size of the breeding program, taking into account short and long term genetic response. In "open" nucleus breeding system, large foundation populations become an integral part of the whole breeding system which leads to screen large populations of animals for the highest producers. Sourcing animals from a wide gene pool for an open nucleus is the most appropriate management strategy to increase the rate of genetic improvement and offset inbreeding degeneration in most nucleus flocks. Actually, without increasing the number of animals in the nucleus, by annually screening elite animals from commercial flocks and replacing nucleus animals with younger breeding stocks together with the accuracy of selection decisions, breeders could raise the standard of the nucleus flock, increase the effective size of the nucleus, ensure high selection intensities and shorter generation intervals, hence hastens genetic progress in productive traits.

\section{REFERENCES}

Abdel-Salam, S. A., Sayed A. I., Manal Elsayed, Abou-Bakr S. (2010). Genetic gain in open nucleus breeding scheme to improve milk production in Egyptian Buffalo. Livestock Science, 131: 162-167.

Analla, M.; Sanchez, A.; Munaz, A., Serradilla, J. M. (1995). Simulation analysis with BLUP methodology of different data structure in goat selection schemes in Spain. Small Ruminant Research, 17:51. 
Boldman, K. G., Kriese, L. A., Van Vleck, L. D., Van Tassell, C. P. (1995). A manual for use of MTDFREML a set of programs to obtain estimates of variance and covariance. Agricultural Research Service, U. S. Department of Agriculture, Washington.

Bosso, N. A. (2006). Genetic improvement of livestock in tsetse infested areas in West Africa. PhD thesis, Wageningen University, The Netherlands.

El-Wakil, Salwa I., Manal ElSayed, Ahmed A. M., Sadek R. R., Nigm A. A. (2009). Genetic and phenotypic parameters of birth, weaning and yearling body weights of Barki sheep raised in the north-western coast of Egypt. Egyptian Journal of Animal Production, 46(1): 43-52.

Gandini, G., Del Corvo M., Biscarini F., Stella A. (2014). Genetic improvement of small ruminant local breeds with nucleus and inbreeding control: A simulation study. Small Ruminant Research, Volume 120 (2-3): 196-203.

Garrick,D. J., Blair H.T., Clarke J. N. (2000). Sheep industry structure and genetic improvement. Proceedings of the New Zealand Society of Animal Production, (60): 175-179.

Hodges, J. (1990). Genetic improvement of livestock in developing countries using the open nucleus breeding system. In: Animal Science Papers and Reports 6, Polish Academy of Sciences, Institute of Genetics and Animal Breeding, Jastrz ebiec, Proceedings of the FAO Conference on Open Nucleus Breeding Systems held at Białobrzegi, Poland, 11-19 June 1989. Polish Scientific Publishers, Warszawa, pp. 13-22.

Jackson, N. and Turner H. N. (1972). Optimal structure for a co-operative nucleus breeding system. Proceeding of the Australian Society of Animal Production, 9: 55-64.

James, J.W. (1977). Open nucleus breeding systems. Animal Production, 24: 287-305.

Kiwuwa, G.H. (1992). Breeding strategies for small ruminant productivity in Africa. In: Rey, B., Lebbie, S.H.B., Reynolds, L. (Eds.), Small Ruminant Research and Development in Africa, Proceedings of the First Biennial Conference of the African Small Ruminant Research Network, ILRAD, Nairobi, Kenya, 10-14 December 1990, pp. 423-434.

Mueller J.P., James J.W. (1984). Development in open nucleus breeding systems. INTA Bariloche, Comunicación Técnica PA Nro. 175. Trabajo presentado al Segundo Congreso Mundial de Ovinos y Bovinos de Carne, Pretoria, Sudáfrica, 16-19 abril de 1984 y publicado en los correspondientes Proceedings (Editores J. Hofmeyery E. Meyer), page 204-213.

Rae, A. L. (1974). The development of group breeding schemes: some theoretical aspects. Sheep farming Annual, P.121-127.

SAS. (2004). Statistical Analysis System. SAS User's Guide: Statistics. SAS Institute Inc. Editors, Cary, NC.

Smith, C. (1988). Genetic improvement of livestock in developing countries using nucleus breeding units. World Animal Review, 65: 2-10. 
Syrstad, O. (1989). The role and mechanisms of genetic improvement in production systems constrained by nutritional and environmental factors. FAO Consultation on Feeding Dairy Cows in the Tropics held in Thailand in the FAO Regional Office for Asia and the Pacific in Bangkok, 3-7 July 1989. Etude FAO Production et Santé Animales 86, pp. $48-55$.

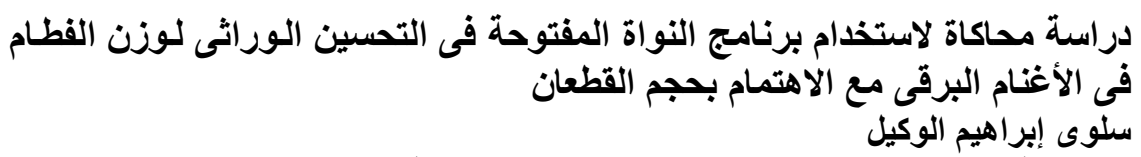
قسم تربية الحيوان والدواجن ، مركز بحوث الصحراء، المطرية، القاهرة، مصر

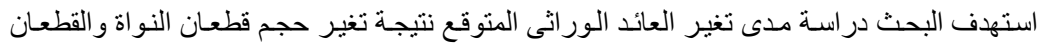

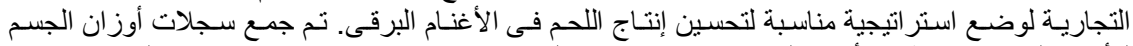

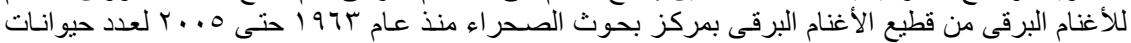

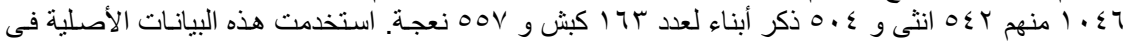

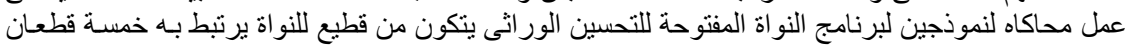

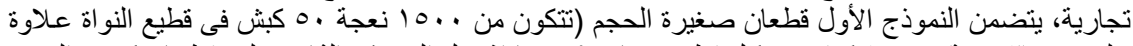

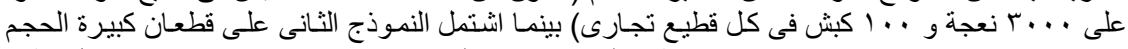

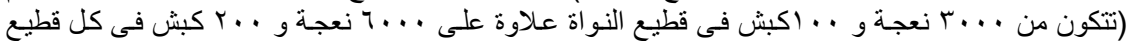

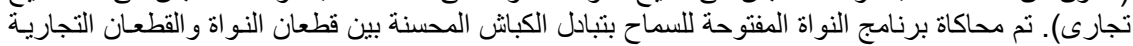

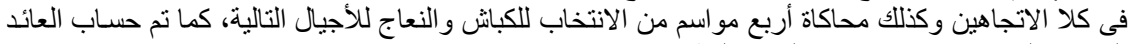

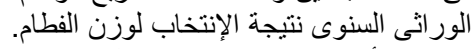

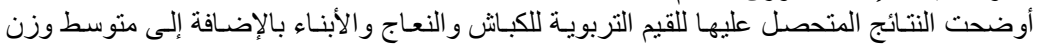

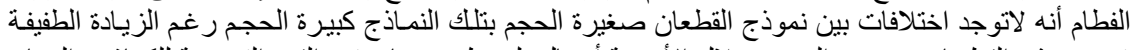

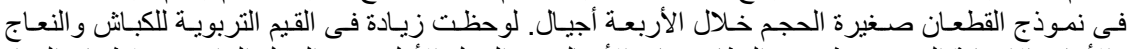

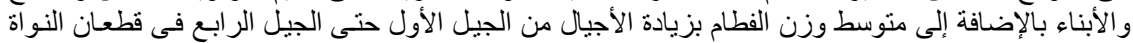

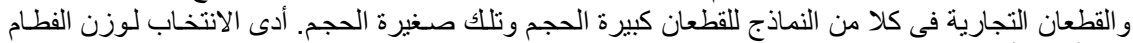

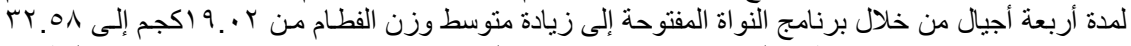

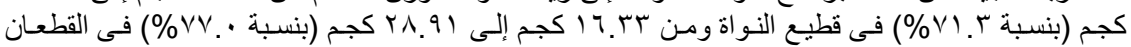

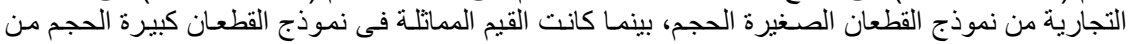

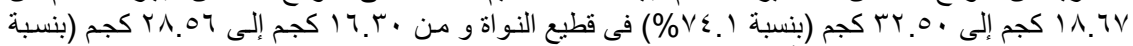

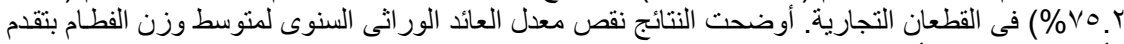

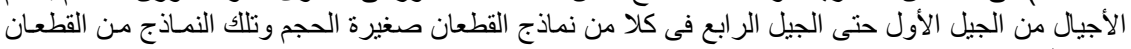

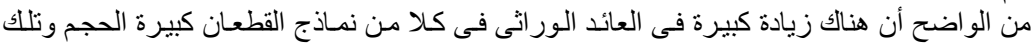
كبيرة الحجم.

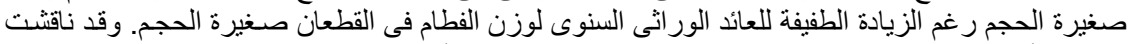

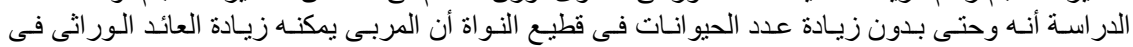

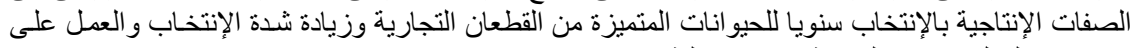
نقص مدة الجيل علاوة على دقة وكفاءة عملية الإنتخاب. 